\title{
Reply to: Percutaneous Vertebral Augmentation for the Treatment of Symptomatic Schmorl's Nodes: Our Viewpoint and Experience
}

\section{TO THE EDITOR:}

We thank Sun et al for their interest in our study on percutaneous vertebroplasty (PVP) in painful Schmorl's nodes (SNs) (1). In response to their concerns and opinions, we would like to clarify the following points:

There is obvious oedematous rim around SNs in T2 weighted Magnetic Resonance Imaging (MRI) presented in our article, which is regarded as the evidence diagnosing symptomatic SNs (2). Moreover, there is still no evidence to identify that the more significant oedematous rim, the higher degree of pain caused by SNs. So, it is possible that the $\mathrm{SN}$ are symptomatic even the oedematous rim in MRI is not so significant.

In our article, we stated that "The symptoms associated with some SNs may be due to inflammatory changes around the herniated nucleus pulposus of the diseased vertebra" (1). But we didn't describe the specific mechanism about it. Micromovements, inflammation and pressure on nociceptors within the oedematous area probably induce back pain, as Sun et al concluded $(3,4)$.

Sun et al reported their study about the effectiveness and safety of percutaneous kyphoplasty (PKP) to symptomatic SNs. Their thoughtful research identified that PKP could be regarded as an effective and safe approach to symptomatic SNs refractory to conservative therapy. They propose the use of PKP over PVP as a therapeutic strategy in patients with symptomatic SNs with the reason that PKP can reduce the probability of cement leakage when comparing with PVP (5). However, there is still no evidence showing that PKP is superior to PVP in treating vertebral compression fractures (VCFs) (6). As Sun et al said, there is clear evidence that cement extravasation is less frequent for PKP than for PVP due to lower cement injection pressure following balloon cavity creation, which is the most important advantage of PKP over PVP $(7,8)$. Also, PKP resulted in greater kyphosis correction (9). However, several studies demonstrated that there is no difference between PKP and PVP when regarding the pain reduction $(7,10-12)$. A large retrospective review comparing conservative therapy, PVP and PKP using Medicare date, found that both PVP and PKP improved survival (13). Considering the lower costs, some researchers preferred PVP for the treatment of VCFs (14). So, further consideration must be given to identify which procedure is better to VCFs.

\section{Acknowledgment}

This project is supported by "the Fundamental Research Funds for the Central Universities" and "the Scientific Research Innovation Program for College and University Graduates of Jiangsu Province (KYZZ16_0133)".
Shi-Cheng He, MD
Department of Radiology
Zhongda Hospital, Medical School
Southeast University
87 Dingjiaqiao Road
Nanjing 210009, China
Bin-Yan Zhong, MD
Department of Radiology
Zhongda Hospital, Medical School
Southeast University
87 Dingjiaqiao Road
Nanjing 210009, China
Hai-Dong Zhu, MD
Department of Radiology
Zhongda Hospital, Medical School
Southeast University
87 Dingjiaqiao Road
Nanjing 210009, China
Gao-Jun Teng, MD, PhD
Department of Radiology
Zhongda Hospital, Medical School
Southeast University
87 Dingjiaqiao Road
Nanjing 210009, China
E-mail: gjteng@vip.sina.com 


\section{References}

1. He SC, Zhong BY, Zhu HD, Fang W, Chen L, Guo JH, Deng G, Teng GJ. Percutaneous Vertebroplasty for Symptomatic Schmorl's Nodes: 11 Cases with Longterm Follow-up and a Literature Review. Pain Physician 2017; 20:69-76.

2. Takahashi K, Miyazaki T, Ohnari H, Takino T, Tomita K. Schmorl's nodes and lowback pain. Analysis of magnetic resonance imaging findings in symptomatic and asymptomatic individuals. Eur Spine J 1995; 4:56-59.

3. Mattei TA, Rehman AA. Schmorl's nodes: current pathophysiological,diagnostic, and therapeutic paradigms. Neurosurg Rev 2014; 37:39-46.

4. Kyere KA, Than KD, Wang AC, Rahman SU, Valdivia-Valdivia JM, La Marca F, Park P. Schmorl's nodes. Eur Spine J 2012; 21:2115-2121.

5. Yang H, Liu H, Wang S, Wu K, Meng B, Liu T. Review of Percutaneous Kyphoplasty in China. Spine (Phila Pa 1976) 2016; 41 Suppl 19:B52-B58.

6. Tsoumakidou G, Too CW, Koch G, Caudrelier J, Cazzato RL, Garnon J, Gangi A. CIRSE Guidelines on Percutaneous Vertebral Augmentation. Cardiovasc Inter- vent Radiol 2017; 40:331-342.

7. Papanastassiou ID, Phillips FM, Van Meirhaeghe J, Berenson JR, Andersson GB, Chung G, Small BJ, Aghayev K, Vrionis FD. Comparing effects of kyphoplasty, vertebroplasty, and non-surgical management in a systematic review of randomized and non-randomized controlled studies. Eur Spine J 2012; 21:18261843.

8. Xing $D, M a ~ J X, M a X L$, Wang J, Xu WG Chen $\mathrm{Y}$, Song $\mathrm{DH}$. A meta-analysis of balloon kyphoplasty compared to percutaneous vertebroplasty for treating osteoporotic vertebral compression fractures. J Clin Neurosci 2013; 20:795-803.

9. Wang H, Sribastav SS, Ye F, Yang C, Wang J, Liu H, Zheng Z. Comparison of percutaneous vertebroplasty and balloon kyphoplasty for the treatment of single level vertebral compression fractures: A Meta-analysis of the literature. Pain Physician 2015; 18:209-222.

10. De Negri P, Tirri T, Paternoster G, Modano P. Treatment of painful osteoporotic or traumatic vertebral compression fractures by percutaneous vertebral augmentation procedures: A nonrandom- ized comparison between vertebroplasty and kyphoplasty. Clin J Pain 2007; 23:425430.

11. Schofer MD, Efe T, Timmesfeld N, Kortmann HR, Quante M. Comparison of kyphoplasty and vertebroplasty in the treatment of fresh vertebral compression fractures. Arch Orthop Trauma Surg 2009; 129:1391-1399.

12. Han S, Wan S, Ning L, Tong Y, Zhang J, Fan S. Percutaneous vertebroplasty versus balloon kyphoplasty for treatment of osteoporotic vertebral compression fracture: A meta-analysis of randomised and non-randomised controlled trials. Int Orthop 2011; 35:1349-1358.

13. Chen AT, Cohen DB, Skolasky RL. Impact of nonoperative treatment, vertebroplasty, and kyphoplasty on survival and morbidity after vertebral compression fracture in the medicare population. J Bone Joint Surg Am 2013; 95:1729-1736.

14. Liu JT, Li CS, Chang CS, Liao WJ. Longterm follow-up study of osteoporotic vertebral compression fracture treated using balloon kyphoplasty and vertebroplasty. J Neurosurg Spine 2015; 23:94-98. 